\title{
Measurement of temperature dependent heat flow rate from human limbs towards thermoelectric cooling device
}

\author{
Gorden Link ${ }^{1}$ and Martin Stelzle ${ }^{1 *}$ \\ ${ }^{1}$ NMI Natural and Medical Sciences Institute at the University of Tübingen, Reutlingen, Markwiesenstrasse 55, 72770 Reutlingen, Germany
}

\begin{abstract}
Regulated cooling devices promise improved outcomes with respect to pain relief and speed of rehabilitation after injuries of the musko-skeletal system when compared to frozen ice cooling pads. Their proper design, however, requires knowledge about heat flow rate from the human body as a function of temperature and location on the body. Accordingly, a measurement device was developed and applied to the measurement of heat flow rate from different locations on the limbs of a male individual. Heat flow rates ranging from $30 \mathrm{~mW} / \mathrm{cm}^{2} @ 25^{\circ} \mathrm{C}$ to $62 \mathrm{~mW} / \mathrm{cm}^{2} @ 15^{\circ} \mathrm{C}$ were determined.
\end{abstract}

Highlights

Heatflow through human skin

Measurement system enabling measurement of heat flow rate as a function of temperature and location on the body

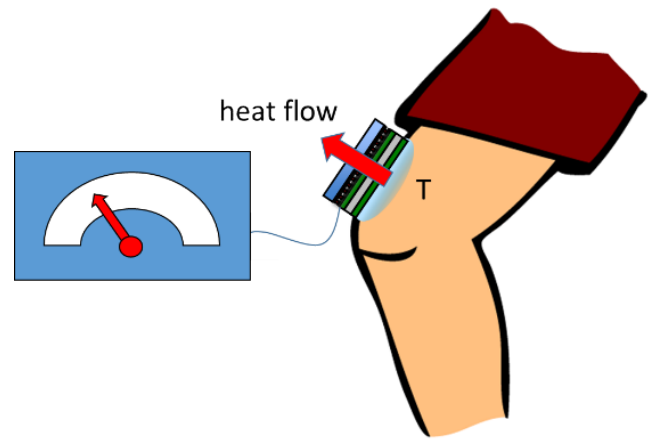

Graphical Abstract

\section{Introduction}

External cooling by application of a cooling bandage is part of the treatment of choice in case of strain traumata, spraining, rupture of ligaments as well as a follow up treatment after surgical intervention to suppress pain and induce deswelling [1-4]. Usually, cooling bandages comprising frozen water ice are employed for this purpose [5]. However, their temperature is lower than ideal which may hamper the healing process and even bears the risk of frostbite [6,7]. Ideally, a temperature in the range from 15 to 25 degree $C$ should be applied and kept constant in order to achieve at least to some degree a pain relieve and deswelling while avoiding hyperthermia of tissue and the undesired inhibition of the healing process associated therewith [8].

To achieve this, temperature regulated cooling devices are envisioned. For their design, information with regard to the heat flow rate from tissue as a function of temperature and location on the body is necessary.

The present short communication presents a method to measure heat flow rate from different areas of the body and data obtained from a healthy male individual, age 53, body mass index 23 .

\section{Method}

Heat flow rate per unit area, j, can be measured by determining the temperature drop

$$
\Delta T=T_{1}-T_{2}
$$

over a thermal resistance, $\mathrm{R}$, of known value according to

$$
j=\frac{\Delta T}{R}
$$

Based on this principle, the device depicted schematically in Figure 1 was developed.

Correspondence to: Dr. Martin Stelzle, NMI Natural and Medical Sciences Institute at the University of Tübingen, Reutlingen, Markwiesenstrasse 55, 72770 Reutlingen, Germany +49 712151530 75; Martin.stelzle@nmi.de

Key words: heat flow rate, human skin, heat flow rate measurement, cooling bandage

Received: March 03, 2017; Accepted: March 29, 2017; Published: March 31, 2017 


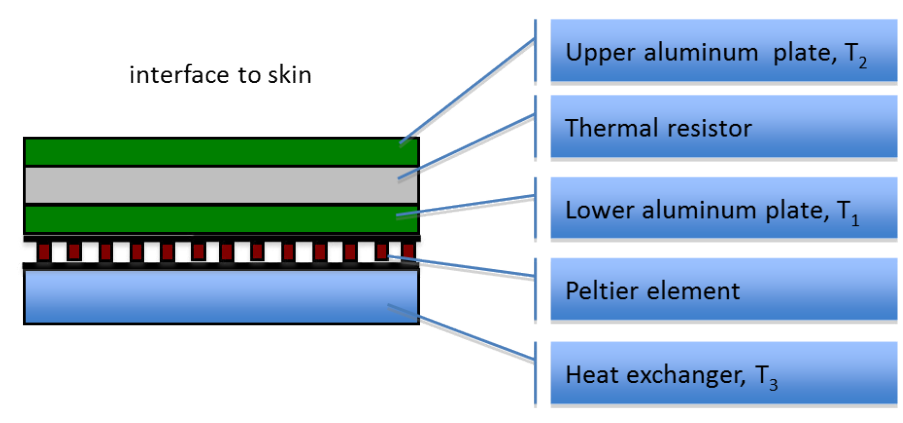

Figure 1. Measurement of heat flow rate (schematically). A peltier element is used to control the temperature $\mathrm{T}_{1}$ at the lower aluminum plate in such a way, that heat flow through the thermal resistor will result in attaining a certain target temperature, $T_{2}$, at the surface of the skin. The resulting heat flow rate may be calculated from the temperature difference $\mathrm{T}_{2}-\mathrm{T}_{1}$ and the known value of the thermal resistor. The temperature on the rear side of the peltier element is kept virtually constant through a heat exchanger coupled to a thermostat.

A peltier element is used to control the temperature on the lower aluminum plate, i.e. on one of the terminals of the thermal resistor. The thermal resistor separates the lower aluminum plate from the upper aluminum plate with the latter being used to establish contact to the skin surface, thus representing the second terminal of the thermal resistor. The thermal resistor consists of a plate of either polycarbonate, exhibiting a specific heat conductance of $0,2 \mathrm{~W} / \mathrm{K}^{\star} \mathrm{m}$ and a thickness of $8 \mathrm{~mm}$ or of polyacrylamide, with a specific heat conductance of $0,19 \mathrm{~W} / \mathrm{K}^{\star} \mathrm{m}$ and a thickness of $3 \mathrm{~mm}$. Since the specific heat conductance of aluminum is by a factor of about 1000 higher, it may be neglected for all practical purposes here.

The temperatures in both the lower and the upper aluminum plates and on the rear side of the peltier element are measured by means of PT1000 temperature sensors.

The contact area of the interface to the skin, i.e. the upper aluminum plate, was $4 \mathrm{~cm} \times 4 \mathrm{~cm}$ in all experiments.

In order to determine the heat flow rate through the skin, the device was affixed to the area of interest, by means of tape, while paying particular attention to provide proper thermal contact and at the same time avoiding excessive pressure, which might otherwise lead to obstruction of blood flow and false readings.

Next, the target temperature, $T_{2}$, was set on the temperature controller and the peltier element cooled down. Due to the high thermal capacity of the system comprised of the tissue, skin and aluminum plate in combination with relatively large thermal resistor values, a considerable degree of ringing was observed until the temperature at the surface of the peltier device, $\mathrm{T}_{1}$, reached a steady state enabling precise determination of the temperature difference $\Delta \mathrm{T}$ and the heat flow rate, respectively (Figure 2). Steady state was achieved in all cases after about 5-15min after setting the target temperature. Relatively large values of the thermal resistance were chosen in order to provide for sufficiently large temperature differences, $\Delta \mathrm{T}$, even with the relatively small heat flow rates expected here, thus enabling precise readings.

\section{Results}

The measurement principle was demonstrated and heat flow rate was determined on different locations on the limbs of a healthy male, age 53 , body mass index 23 . The heat flow rate ranges from about $30 \mathrm{~mW} / \mathrm{cm}^{2} @ 25^{\circ} \mathrm{C}$ surface temperature to $62 \mathrm{~mW} / \mathrm{cm}^{2} @ 15^{\circ} \mathrm{C}$ for measurements on wade above and below the knee joint, respectively and the foot ankle (Figure 3 and Table 1). In contrast, heat flow rate is about twice as high from the thenar, where blood flow is high and the thickness of subcutaneous fat layer is low. This result is in agreement with the fact, that fat tissue exhibits a thermal conductivity of approximately 0.2 to $0.25 \mathrm{~W} / \mathrm{m}^{\star} \mathrm{K}$ whereas thermal conductivity in perfused muscle tissue is about 0.45 to $0.55 \mathrm{~W} / \mathrm{m}^{\star} \mathrm{K}$, certainly due to the strong perfusion of muscle in contrast to fat tissue [9].

\section{Conclusion}

A versatile method and device to determine heat flow rate from different body areas was developed and demonstrated on different locations on the body of a male adult.

In the future, an improved device will include improved adjustment of control parameters of the PID-controller in order to reduce ringing and attain measurement values more rapidly.

These kind data will enable proper and efficient design of temperature controlled cooling devices for medical application.

Table 1. Summarized values of heat flow rate through skin from a male individual, age 53, body mass index 23 .

\begin{tabular}{|c|c|c|c|}
\hline Skin temperature $\left[{ }^{\circ} \mathrm{C}\right]$ & 15 & 20 & 25 \\
\hline Heat flow rate $\left[\mathrm{mW} / \mathrm{cm}^{2}\right]$ & $62+/-6$ & $48+/-4$ & $30+/-4$ \\
\hline
\end{tabular}
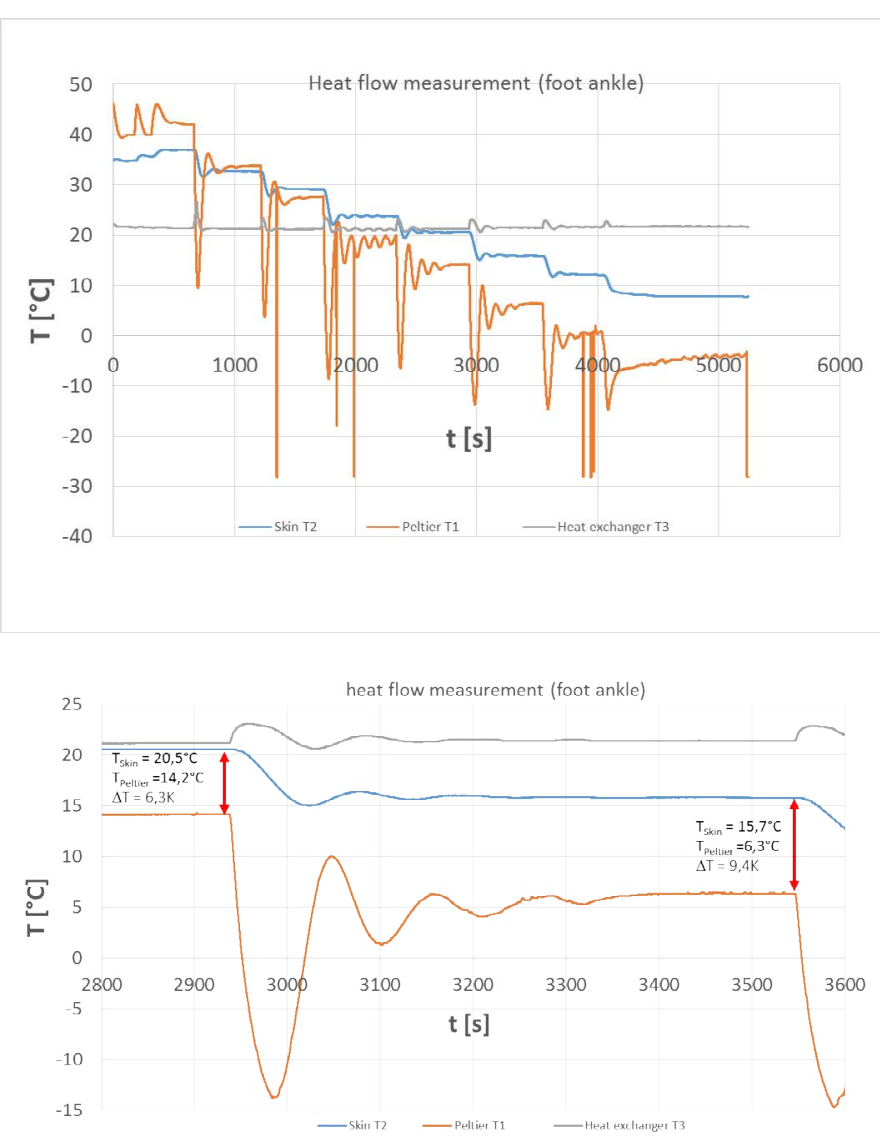

Figure 2. Measurement of temperature differences between skin surface and peltier surface in order to obtain heat flow rate. a) time course over a $2 \mathrm{~h}$ experiment shows sequential reduction of target temperature and the attainment of a stable steady state within about 5 $15 \mathrm{~min}$, enabling precise determination of temperature on the peltier element (b). 


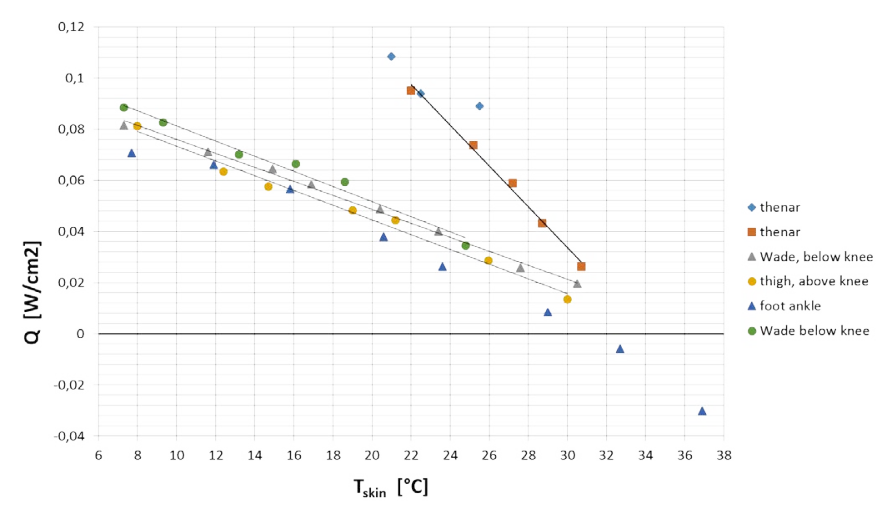

Figure 3. Heat flow rate as function of skin temperature and location. While measurements on wade above and below the knee as well as on the foot ankle show similar slope, i.e. hea flow rate as a function of skin temperature, heat flow rate through the thenar is almost twice as high. Also, the lower than $37^{\circ} \mathrm{C}$ surface temperature at the distal end of limbs becomes obvious from the measurement on the foot ankle, as heat flow is reversed at temperatures above $32^{\circ} \mathrm{C}$.

\section{Acknowledgements}

This research was in part funded by grant KF2053913RE4 through the ministry of commerce and energy (BMWi) of Germany.

\section{References}

1. Nadler SF, Weingand K, Kruse RJ (2004) The physiologic basis and clinical applications of cryotherapy and thermotherapy for the pain practitioner. Pain Physician 7: 395-399.[Crossref]

2. Ernst E, Fialka V (1994) Ice freezes pain? A review of the clinical effectiveness of analgesic cold therapy. J Pain Symptom Manage 9: 56-59.[Crossref]

3. Khoshnevis S, Craik NK, Diller KR (2015) Cold-induced vasoconstriction may persist long after cooling ends: an evaluation of multiple cryotherapy units. Knee Surgery, Sports Traumatology, Arthroscopy 23: 2475-2483.

4. Rana M (2013) 3D evaluation of postoperative swelling in treatment of bilatera mandibular fractures using 2 different cooling therapy methods: A randomized observer blind prospective study. Journal of Cranio-Maxillofacial Surgery 41: e17-e23.

5. Konrath GA (1996) The Use of Cold Therapy After Anterior Cruciate Ligament Reconstruction: A Prospective, Randomized Study and Literature Review. The American Journal of Sports Medicine 24: 629-633.

6. McGuire DA, Hendricks SD (2006) Incidences of Frostbite in Arthroscopic Knee Surgery Postoperative Cryotherapy Rehabilitation. Arthroscopy: The Journal of Arthroscopic \& Related Surgery 22: 1141.e1-1141.e6.

7. Brown WC, Hahn DB (2009) Frostbite of the feet after cryotherapy: a report of two cases. J Foot Ankle Surg 48: 577-580.[Crossref]

8. Cuttle L, Kempf M, Kravchuk O, Phillips GE, Mill J, et al. (2008) The optimal temperature of first aid treatment for partial thickness burn injuries. Wound Repair Regen 16: 626-634.[Crossref]

9. Valvano JW, Allen JT, Bowman HF(1984) The Simultaneous Measurement of Thermal Conductivity, Thermal Diffusivity, and Perfusion in Small Volumes of Tissue. Journal of Biomechanical Engineering 106:192-197.

Copyright: (C2017 Link G. This is an open-access article distributed under the terms of the Creative Commons Attribution License, which permits unrestricted use, distribution, and reproduction in any medium, provided the original author and source are credited. 